\title{
Cost of rheumatoid arthritis in a selected population from Argentina in the prebiologic therapy era
}

This article was published in the following Dove Press journal:

ClinicoEconomics and Outcomes Research

22 August 2012

Number of times this article has been viewed

\section{Erika Catay' \\ Cecilia Castel del Cid' \\ Lorena Narváez' \\ Edson J Velozo' \\ Javier E Rosa ${ }^{1,2}$ \\ Luis J Catoggio 1,2 \\ Enrique R Soriano ${ }^{1,2}$}

'Rheumatology Unit, Internal Medicine Service, Hospital Italiano de Buenos Aires, ${ }^{2}$ University Institute Hospital Italiano de Buenos Aires, School of Medicine, PM Catoggio Foundation, Buenos Aires, Argentina
Correspondence: Enrique R Soriano Hospital Italiano de Buenos Aires, Peron 4190 (CI I 99ABB), Ciudad Autonoma de Buenos Aires, Argentina Tel +54 II 49590378

Fax +54 II 49590378

Email enrique.soriano@hospitalitaliano. org.ar
Background: The present study aimed to estimate the cost of rheumatoid arthritis and its components in a university hospital-based health management organization in Argentina, during the prebiologic era.

Methods: A one-year (2002) observational prevalence, cost-of illness study of patients with rheumatoid arthritis from the societal perspective was performed in a hospital-based health management organization population. Direct medical costs were obtained using administrative databases. Direct nonmedical and indirect costs were obtained from a semistructured questionnaire. Indirect costs included work absenteeism, permanent work disability, and housework lost for housewives, using the human capital approach. Costs are expressed in 2002 US dollars per patient per year.

Results: A total of 165 patients (84\% females), of mean age $61 \pm 15$ years and with a mean disease duration of $8.5 \pm 8.3$ years were included. Mean total direct medical costs were US\$1862 (95\% confidence interval [CI] 828-2899). Mean direct nonmedical costs were US\$222 (95\% CI 149-294). Mean indirect costs were US\$1008 (95\% CI 606-1412). The annual mean total cost was US\$3093 without biologics. Hospitalizations represented $73 \%$ of total direct medical costs while drugs and outpatient procedures represented $16 \%$ and $8 \%$ of total direct medical costs, respectively. Sixty percent of the total costs were related to direct medical costs, while indirect costs represented $33 \%$ of total costs.

Conclusion: In our population, annual mean total costs in the prebiologic therapy era were mainly driven by direct medical costs. Even without the use of biologic agents, rheumatoid arthritis represents an important burden for society in developing countries.

Keywords: rheumatoid arthritis, economics, burden of illness, cost of illness

\section{Introduction}

Rheumatoid arthritis is a chronic systemic inflammatory disabling disorder affecting $0.2 \%-1 \%$ of the population worldwide. In Argentina, the prevalence of rheumatoid arthritis has been estimated to be $0.2 \%-0.94 \%$ in population-based studies. ${ }^{1-3}$ Rheumatoid arthritis imposes a considerable burden on society in terms of morbidity, long-term disability, and costs. ${ }^{4,5}$ The quantification of all costs associated with a particular disease are used as a proxy for the medical and economic burden that the disease places upon society. ${ }^{5}$ Such studies are known as cost-of-illness studies or burden-of-illness studies. ${ }^{5,6}$

Burden-of-illness analysis, by assessing the use of health care resources and detailing the cost components involved, gives additional insight into the magnitude of the disease and its consequences. ${ }^{7}$ On the other hand, burden-of-illness studies provide 
the bases for cost calculations in the cost-effectiveness analysis. ${ }^{8}$ In the era prior to biologic treatments, direct medical costs of rheumatoid arthritis have been estimated at 5700-5800 US dollars per year in the US. ${ }^{9}$ Drugs represented $8 \%-24 \%$ of direct medical costs, while hospital admission represented $60 \%-80 \%{ }^{9}$

There is very scarce information on the burden of rheumatoid arthritis in developing countries, in particular for Latin America. ${ }^{10-13}$ Resource availability is limited in many sectors in Argentina, including the health care system. To optimize utilization of the scant resources available, it is essential to conduct systematic economic evaluations of health interventions, as well as to develop an awareness of how these costs break down and are utilized. To date, there have been no studies on resource allocation and the cost of rheumatoid arthritis from a societal perspective in Argentina. The objective of this study was to explore the burden of rheumatoid arthritis in a health management organization (HMO) in Argentina, including cost and components of costs from a societal perspective in the prebiologic era.

\section{Materials and methods}

We performed a one-year (2002) observational, retrospective, prevalence "bottom-up", sum-all medical, cost-of-illness study from the societal point of view. All patients affiliated to the Hospital Italiano de Buenos Aires HMO (Plan de Salud) identified in an earlier prevalence study ${ }^{1}$ and fulfilling the inclusion criteria were included. All patients met the American College of Rheumatology 1987 revised criteria for the classification of rheumatoid arthritis. ${ }^{14}$ Eligible patients had to fulfill the following criteria: age $>18$ years; continuous affiliation with the Plan de Salud during 2002 (except for dropouts due to death). Ethical approval for this study was obtained from the hospital institutional review board.

\section{Setting}

The Plan de Salud is an HMO with its medical care based in a university hospital which is part of the private health insurance subsystem in Argentina. Argentina's health system is divided into three major subsystems as follows.

\section{Public subsystem}

The public subsystem is open to the whole population but mainly used by those without voluntary or compulsory insurance (mainly unemployed or on the "black" labor market), representing around $40 \%$ of the total population.

\section{Social security subsystem}

The social security subsystem involves central agents of the health insurance system covering the population insured under a compulsory insurance system (income-related contributions by employers and employees), representing $52 \%$ of Argentina's population. This subsystem includes the national social security institute for retirees and pensioners (PAMI) which is under a special regime, and covers $22.4 \%$ of the population under the compulsory insurance system, and its resources come from contributions from active and retired workers.

\section{Private insurance or voluntary insurance subsystem}

The third subsystem is the private insurance or voluntary insurance model containing the Plan de Salud, and covers around $7 \%$ of the higher-income population in Argentina. Patients voluntarily affiliate with the Plan de Salud and with a monthly prepaid system acquire full coverage for all medical events (including ambulatory and inpatient care), and 60\% coverage for all prescribed medications. Since 1999, the Plan de Salud has had a problem-oriented electronic medical record system in which all medical encounters and diagnoses are registered. During the year 2002, Plan de Salud had around 70,000 affiliated adult members. Ninety percent of all Plan de Salud and its affiliates are individual bodies as opposed to institutional affiliations.

\section{Data sources}

Data for health care utilization and direct medical costs were obtained from the HMO administrative and medical databases. Clinical data were obtained from the first Rheumatology visit during year 2002. Clinical assessments included demographics and the Argentine validated version of the Health Assessment Questionnaire (HAQ) disability index. ${ }^{15}$ Nonmedical direct costs (transportation) and indirect costs incurred in the previous 12 months were assessed by a semistructured cost questionnaire administered at the same visit.

\section{Direct medical costs}

All costs were included (sum-all medical). ${ }^{6}$ Direct medical costs comprised the costs related to medications (including out-ofpocket payment for prescribed medications), laboratory tests and procedures, hospitalizations, medical and other allied health professional outpatient visits, and rehabilitation. Complementary practitioners, eg, chiropractors and acupuncturists, were not included. Direct medical costs and health care utilization were 
obtained from the HMO administrative database, and reflect charges to the HMO without adjustment, and are expressed in US dollars for the year 2002 .

\section{Direct nonmedical costs}

Patients and family members and/or caregiver transportation costs were included and obtained from the cost questionnaire.

\section{Indirect costs}

Indirect costs included the cost estimates resulting from work absenteeism by patients and their family members, and the patient's loss of productivity because of early retirement due to rheumatoid arthritis (permanent work disability). For those in the labor force (full-time and part-time) and family members, the human capital approach ${ }^{16}$ was used, considering the average Argentine wage rate in the year 2002 (US\$588 per month) to value the lost time. The following formula was used:

\section{Mean monthly Argentine wage $/ 20 \times$ number of reported days lost}

For those who were permanently disabled, implicit one-year income losses were calculated using average Argentine wage rates. For housewives, the replacement cost approach was used, ie, multiplying the number of selfreported days unable to attend to domestic duties by market values to perform equivalent duties at home ( $\$ 1.79$ US per hour $\times 8$ hours a day). All these indirect cost data were obtained from the cost questionnaire.

\section{Statistical analysis}

Demographic and disease characteristics of the patients are presented using descriptive statistics. Health care utilization is presented as the mean \pm standard deviation or median and interquartile range (IQR) according to variable distribution. Costs are presented as mean annual values per patient in 2002 US dollars without adjustment. Costs were also compared between patients according to disability status measured by HAQ ( $<$ or $>0.8$ as a dichotomous variable). Statistical analysis was performed using STATA statistical software, version 8.0 (Stata Corporation, College Station, TX).

\section{Results}

One hundred and sixty-five patients were included in this study. Patient demographics and work-related characteristics are summarized in Table 1 . Mean age at study entry was $62 \pm 15$ years, and mean disease duration was $8.5 \pm 8.3$ years. All patients had
Table I Demographic and work-related characteristics of 165 patients with rheumatoid arthritis

\begin{tabular}{|c|c|}
\hline Females, n (\%) & $139(84)$ \\
\hline Mean age (SD), years & $62 \pm 15$ \\
\hline Mean age (SD) at diagnosis, years & $54 \pm 17$ \\
\hline Mean disease duration (SD), years & $8.5 \pm 8.3$ \\
\hline Positive rheumatoid factor, $\%(n=148)$ & 71 \\
\hline Mean years of education (SD) & $11.5 \pm 4.1$ \\
\hline Mean HAQ $(n=132)$, SD & $0.9 \pm 0.7$ \\
\hline Hypertension, \% $(\mathrm{n}=\mathrm{III})$ & 49 \\
\hline Diabetes mellitus, $\%(n=11 \mathrm{I})$ & 11.5 \\
\hline Hyperlipidemia, \% $(n=1 \mathrm{II})$ & 24.4 \\
\hline Cigarette smoking ever, \% $(\mathrm{n}=\mathrm{II} \mathrm{I})$ & 7.7 \\
\hline Retired, \% $(n=90)$ & 18 \\
\hline Permanent work disability, \% $(n=90)$ & 7 \\
\hline Working full time, $\%(n=90)$ & 48 \\
\hline Working part time, $\%(n=90)$ & 19 \\
\hline Full time housewife, $\%(n=90)$ & 16 \\
\hline
\end{tabular}

Abbreviations: SD, standard deviation; HAQ, Health Assessment Questionnaire.

full health care coverage because all were affiliated with the Plan de Salud. Table 2 summarizes health care utilization during the study period. The annual incidence of hospitalizations was 254 per 1000 patients (95\% confidence interval [CI] 128-381).

\section{Direct medical costs}

Four primary components of cost (hospitalization, drugs, medical and allied health professional visits, and outpatient procedures) are summarized in Table 3. Mean annual total direct medical cost was US\$1862 \pm US\$6735 per patient (median 460; IQR 221-830). Hospitalizations represented $73 \%$ of total direct medical costs, while drugs and outpatient procedures represented $16 \%$ and $8 \%$ of total direct medical costs, respectively.

\section{Direct nonmedical costs}

Mean annual expenditure for transportation of patients and family members was US\$221.9 \pm US\$315 (95\% CI 149-294; median 107; IQR 17-343).

\section{Indirect costs}

Ninety patients completed the cost questionnaire. There were no differences in demographic characteristics between patients answering the questionnaire and the total study

Table 2 Utilization of health care resources

Annual mean hospital admissions per member (SD) $\quad 0.254 \pm 0.82$

Annual mean medical visits per member (SD)

$15.7 \pm 10.5$

Annual mean outpatient procedures per member (SD)

$52.6 \pm 45.5$

Abbreviation: SD, standard deviation. 
Table 3 Annual mean direct medical costs according to type

\begin{tabular}{lll}
\hline Cost type & $\begin{array}{l}\text { Mean cost per patient } \\
\text { US\$ }(95 \% \mathrm{CI})\end{array}$ & $\begin{array}{l}\text { Percent } \\
(95 \% \mathrm{CI})\end{array}$ \\
\hline Hospitalizations & $1360(355-2363)$ & $73(7 \mathrm{I}-75)$ \\
Medications & $289(244-333)$ & $16(14-17)$ \\
Physician visits & $56(50-6 \mathrm{I})$ & $3(2-4)$ \\
Diagnostic tests & $157(123-19 \mathrm{I})$ & $8(7-10)$ \\
Total annual mean direct & $1862(828-2899)$ & 100 \\
medical cost per patient & & \\
\hline
\end{tabular}

Abbreviation: $\mathrm{Cl}$, confidence interval.

population with rheumatoid arthritis. Table 1 shows the distribution of patients related to their work status. Forty-seven percent (95\% CI 36-57) were working full-time and $18 \%$ (95\% CI 11-28) were full-time housewives.

Table 4 shows work absenteeism and indirect costs. Fiftyeight percent of workers reported at least one day of absenteeism because of their disease. Workers (full-time plus part-time) lost a mean of $17.6 \pm 29.2$ (median $12 ;$ IQR 0-12) days during the year because of the disease, and family members lost a mean of $4 \pm 8.9$ days per year for the same reason.

Housewives were unable to attend their homes for a mean $8.8 \pm 13.4$ days during the year. Six patients $(7 \%$, four females and two males) retired at an early age (mean age of retirement $55 \pm 10$ years) because of permanent disability. The remaining patients (18\%) were retired because of their age alone and were not currently working. Annual mean total indirect cost were US\$1008 (95\% CI 606-1412; median 353; IQR 0-859) per patient.

Table 5 shows cost types according to disability status measured by HAQ in 132 patients in whom HAQ status was available. While direct medical costs were not significantly different in patients with lower or higher HAQ, indirect and total costs were significantly higher in patients with more disability $(\mathrm{HAQ}>0.8)$.

\section{Total costs}

Figure 1 shows the mean total cost and the distribution of its components. Mean annual total cost was US\$3093
(95\% CI 1581-4605) per patient. Sixty percent of total costs were related to direct medical costs, while indirect costs represented $33 \%$ of total costs.

\section{Discussion}

The results of this study indicate that the annual costs of rheumatoid arthritis in the Argentine population during the prebiologic therapy era were approximately 3000 US dollars per patient. Numerous studies exist on the costs of rheumatoid arthritis in many countries; however, there are few studies of costs for adults with rheumatoid arthritis in Latin America and other developing countries. ${ }^{10-13,17}$ It is difficult to compare costs from different countries because of varying definitions of costs and sources of unit costs, as well as differing time periods and exchange rates. ${ }^{17}$

Pugner et $\mathrm{al}^{17}$ reviewed cost studies performed between 1978 and 1998 in the major Organization for Economic Cooperation and Development countries. They reported that the mean annual total cost of rheumatoid arthritis was $\$ 12,210$ per patient, expressed in 1998 US dollars. A review by Cooper of 15 studies $^{5}$ reported direct medical costs averaging US\$5720 (1996 US dollars) and indirect costs of US\$5822. These figures are higher than ours, and this could be explained by the fact that health care is less expensive in Argentina than in developed countries (a medical visit is paid in the US $825 \%$ more than in Argentina (at US\$49.50 $0^{18}$ versus US\$6, and a hand and wrist $\mathrm{x}$-ray is paid $275 \%$ more in the US than in Argentina, at US\$27.5018 versus US\$10).

On the other side, costs in our study were higher than those reported in other Latin American countries, such as Brazil ${ }^{12,13}$ and Colombia. ${ }^{19,20}$ Brazilian authors found a mean direct annual cost per patient of US\$403.04 (2002), ${ }^{13}$ which is lower than our mean of US\$1862. One possible explanation is that they only considered costs related to rheumatoid arthritis, while we took into account all medical costs. Mean numbers of medical visits, diagnostic tests, and hospitalizations were lower in the Brazilian study than in ours.

Table 4 Work absenteeism and indirect costs

\begin{tabular}{llllc}
\hline Occupation & Patients, $\mathbf{n}(\%)$ & $\begin{array}{l}\text { Mean annual days } \\
\text { lost (SD) }\end{array}$ & $\begin{array}{l}\text { Mean annual days } \\
\text { of housework lost }\end{array}$ & $\begin{array}{l}\text { Mean annual cost } \\
\text { (2002 US\$) per patient (SD) }\end{array}$ \\
\hline Full-time workers & $43(48)$ & $21.4 \pm 33$ & $629.16 \pm 974$ \\
Part-time workers & $17(19)$ & $13.6 \pm 24$ & $399.84 \pm 703$ \\
Housewives & $14(16)$ & - & $8.8 \pm 13$ & $126 \pm 192$ \\
Family members & - & $4.3 \pm 8.9$ & - & $126.42 \pm 288$ \\
Permanently disabled & $6(7)$ & - & - & $7056 \pm 0$ \\
Mean annual total & $90(100)$ & & & $1008.8 \pm 1913$ \\
indirect costs per patient (SD) & & & & \\
\hline
\end{tabular}

Abbreviation: SD, standard deviation. 
Table 5 Median direct annual costs and total costs according to HAQ status

\begin{tabular}{llll}
\hline Cost type & \multicolumn{3}{l}{ HAQ status $(\mathbf{n}=\mathbf{I 3 2})$} \\
\cline { 2 - 4 } & $\begin{array}{l}\text { HAQ } \leq \mathbf{0 . 8} \\
(\mathbf{n}=\mathbf{5 7})\end{array}$ & $\begin{array}{l}\text { HAQ }>\mathbf{0 . 8} \\
(\mathbf{n}=\mathbf{7 5})\end{array}$ & $\begin{array}{l}\text { P value (Mann- } \\
\text { Whitney U test) }\end{array}$ \\
\hline Median direct & 393 & 500 & 0.19 \\
annual costs (IQR) & $(269-694)$ & $(302-741)$ & \\
Median indirect & $550.3^{*}$ & $\mid 23 I^{* *}$ & 0.0064 \\
annual costs (IQR) & $(172-123 \mathrm{I})$ & $(636-1839)$ & \\
Median total & $1069.5 *$ & $1649 * *$ & $0.003 \mid$ \\
annual costs (IQR) & $(337-1937)$ & $(1438-1948)$ & \\
\hline
\end{tabular}

Notes: $*_{\mathrm{n}}=37 ; *^{*} \mathrm{n}=49$.

Abbreviations: HAQ, Health Assessment Questionnaire; IQR, interquartile range.

In the first Colombian study, the direct total cost was US\$938 for the first year of disease after diagnosis (taking into account methotrexate as the first-choice treatment). Medications represented more than $50 \%$, followed by the costs of diagnostic tests, while physician's fees represented less than $6 \% .{ }^{19}$ In the other Colombian study, patients with mild and moderate disease (most of them without biologics) were US\$1689, and US\$1805, respectively. ${ }^{19}$ In both studies, patients had early rheumatoid arthritis, where less costs are expected, in particular during the first year. ${ }^{19,20}$ In Mexico, the total annual medical costs were US\$2339, and the main component was use of medication. ${ }^{21}$

More meaningful perhaps than comparing costs between different countries is to look at percent contributions of the various components of costs. A prevalence estimate of the cost of disease can provide information regarding the categories of cost that can be targeted for economic savings. Between one quarter and one half of the costs of rheumatoid arthritis were direct medical costs, and hospitalization was the most important single factor in direct costs in the review by Pugner. ${ }^{17}$ Summarizing 12 studies, the authors found

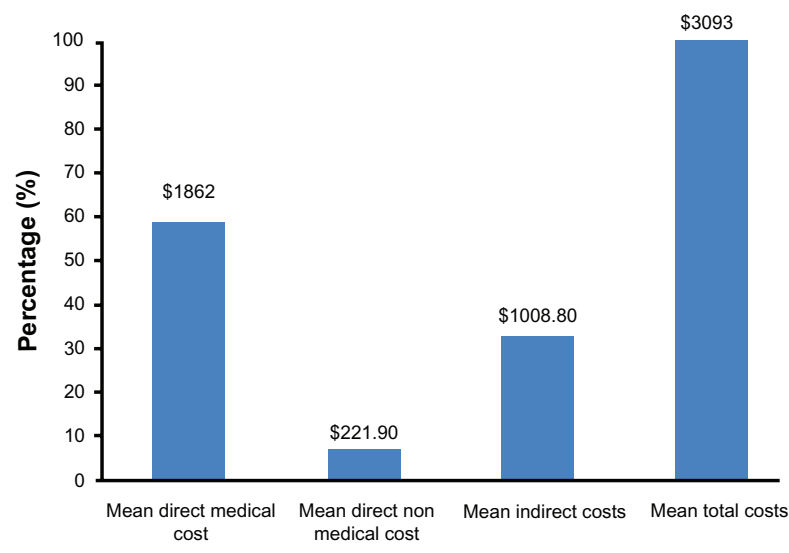

Figure I Mean costs per patient per year in US dollars and percentage distribution by cost type. that hospitalization accounted for a median of $47 \%$ (range $16 \%-67 \%$ ) of direct costs, whereas medication accounted for a median $16 \% .{ }^{17}$ In the review by Cooper, ${ }^{5}$ two of the four studies that estimated both direct and indirect costs reported direct costs to be the largest contributor to total cost $(62 \%-74 \%)^{22,23}$ and two studies reported indirect costs to be approximately twice the direct costs. ${ }^{24,25}$ In that review, medication constituted $8 \%-24 \%$ of total medical costs and inpatient stays $17 \%-88 \%$. $^{5}$

In our study, direct medical costs accounted for $60 \%$, and indirect costs for $33 \%$ of total annual costs. Within the direct medical costs, hospitalizations accounted for $73 \%$ and drug costs for $16 \%$. Thus, hospitalizations accounted for the largest proportion of costs, and represent the area with the largest potential for savings. Interestingly, while patients with more disability measured by HAQ had similar direct medical costs, they had higher indirect and total costs. This result probably reflects the higher work impairment in patients with more disability.

The cost of rheumatoid arthritis and the components thereof changed after the introduction of biologic agents. Direct medical costs became driven by drug costs, and drug costs were mainly driven by biologic therapy in the study by Michaud et al. ${ }^{18}$ The mean total annual direct cost for patients receiving biologic agents was US\$19,016 per year, while the cost for those not receiving biologic therapy was US\$6164. ${ }^{18}$ The high acquisition costs of new therapies are expected to be compensated by savings in employment productivity, given that maintaining people at work is the only way that such agents can be cost-effective. ${ }^{26,27}$

Our study has some inherent limitations. It was performed in an HMO which was part of the private insurance health care subsystem, including patients with higher incomes. Whether this population is representative of the whole Argentine population with rheumatoid arthritis and whether our estimates can be generalized further remains controversial. In a national study of patients with rheumatoid arthritis in Argentina, the patients included were similar to those with rheumatoid arthritis in the rest of the country in terms of demographics, disease activity, disability, and standard of care provided (unpublished data). The characteristics of the study population have an effect on cost estimates. In this sense, our population was similar to that reported in other studies. ${ }^{5}$ Forty-eight percent of our patients were over 65 years of age and many of them were not working or retired. This might have underestimated the impact of temporary work disability, and underestimated indirect costs. The rate of permanent work disability in our study (7\%) was lower than that reported 
in the review by Burton et $\mathrm{al}^{27,28}(20 \%-70 \%)$. A review of 12 cross-sectional studies from Europe and the US found that patients with rheumatoid arthritis had an increased risk of being without paid employment, with odds ratios between 1.2 and 3.4 compared with reference groups ${ }^{29}$ Restriction on employment occurred during the early phase of rheumatoid arthritis and varied between different studies. ${ }^{29}$ Two years after diagnosis, disability benefits increased by up to $30 \%$ in some European countries. ${ }^{29}$ An observational study in the US of work disability in subjects with rheumatoid arthritis found annualized incidence rates of $8.7 \%$ for stopping work and $4.0 \%$ for stopping and not resuming work over a period of 12.8 years. ${ }^{30}$ These differences might be explained, at least in part, by the low disability compensation and retirement wages in our country, which discourage early retirement. The fact that our patients are from a high-income population had no effect on indirect costs because we used the average Argentine wage instead of actual salaries.

For direct medical costs, we included all medical costs, not just costs related to rheumatoid arthritis. This was a population of elderly patients, where some comorbidities are to be expected. We adopted this position because it is not always clear what costs should be attributed strictly to rheumatoid arthritis. Cardiovascular disease has been shown to be more frequent in patients with rheumatoid arthritis, and along with infections and gastrointestinal ulcers, could be considered consequences of rheumatoid arthritis. ${ }^{31-33}$ Lajas et $\mathrm{al}^{34}$ found that only $10 \%$ of global health care costs were not related to rheumatoid arthritis. Although the calculation of incremental costs using a disease-free population is recommended ${ }^{5}$ to avoid the assumption that without the disease of interest a person would incur no cost-of-illness, these data are still relevant for decision-makers, government, and society as a whole.

We used charges rather than costs without adjustment. This could generate some differences when attempting to generalize results to other settings, because the amount billed and paid for a resource may very often be different from its actual cost. However, most studies use charges as proxies for costs, and figures obtained in this way might better reflect the disease burden for society. Finally, the study was performed in 2002, and its results might not exactly reflect the situation today. However, these are still valuable data on health service utilization and costs of patients treated with traditional disease-modifying antirheumatic drugs.

Despite these limitations, our study has the following merits. The study was done in a community-based rather than on a hospital-based population. This provides a more reliable estimate about the impact of rheumatoid arthritis in terms of restriction on activities and medical care utilization, and may be more realistic when generalizing to the overall disease population in our country. We measured real direct medical costs rather than estimating them from mean values, standard costs, or patient's reported use of care, as have earlier studies, ${ }^{5,17}$ giving a more accurate estimate of health care utilization. Finally, we report not only costs, but also health care utilization, which might be more useful for international comparisons.

Our results are consistent with previous studies from other parts of the world. In developing countries, costs are still mainly driven by direct medical costs because they follow international values more closely than national wages. The high acquisition costs of new therapies at their international prices contrasting with the lower economic impact of maintaining employment makes these treatments in developing countries much less cost-effective than in developed countries, and this is a problem that all sectors involved will have to address.

\section{Acknowledgment}

The authors express their gratitude to Mould Joaquin and Tang Boxiong for their valuable comments on the manuscript.

\section{Disclosure}

The study was partially supported by an unrestricted educational grant from Pfizer SA.

\section{References}

1. Soriano E, Carrio J, Schpilberg M, Figar S, Imamura P, Catoggio L. Incidence and prevalence of rheumatoid arthritis in a health management organization in Argentina. Rheumatology. 2003;42 Supp 1:130.

2. Spindler A, Bellomio V, Berman A, et al. Prevalence of rheumatoid arthritis in Tucuman, Argentina. J Rheumatol. 2002;29(6):1166-1170.

3. Scublinsky D, Venarotti H, Citera G, et al. The prevalence of rheumatoid arthritis in Argentina: a capture-recapture study in a city of Buenos Aires province. J Clin Rheumatol. 2010;16(7):317-321.

4. Kvien TK. Epidemiology and burden of illness of rheumatoid arthritis. Pharmacoeconomics. 2004;22(Suppl 2):1-12.

5. Cooper NJ. Economic burden of rheumatoid arthritis: a systematic review. Rheumatology (Oxford). 2000;39(1):28-33.

6. Akobundu E, Ju J, Blatt L, Mullins CD. Cost-of-illness studies: a review of current methods. Pharmacoeconomics. 2006;24(9):869-890.

7. Ben Sedrine W, Radican L, Reginster JY. On conducting burden-ofosteoporosis studies: a review of the core concepts and practical issues. A study carried out under the auspices of a WHO Collaborating Center. Rheumatology (Oxford). 2001;40(1):7-14.

8. Beresniak A, Gossec L, Goupille P, et al. Direct cost-modeling of rheumatoid arthritis according to disease activity categories in France. J Rheumatol. 2011;38(3):439-445.

9. Yelin EH, Henke CJ, Kramer JS, Nevitt MC, Shearn M, Epstein WV. A comparison of the treatment of rheumatoid arthritis in health maintenance organizations and fee-for-service practices. $N$ Engl J Med. 1985; 312(15):962-967. 
10. Osiri M, Maetzel A, Tugwell P. The economic burden of rheumatoid arthritis in a developing nation: results from a one-year prospective cohort study in Thailand. J Rheumatol. 2007;34(1):57-63.

11. Audisio MJ, Strusberg I, Orellana Barrera SD, et al. Semester direct cost by rheumatoid arthritis in patients in a university hospital. Rev Fac Cien Med Univ Nac Cordoba. 2003;60(2):35-41. Spanish.

12. de Azevedo AB, Ferraz MB, Ciconelli RM. Indirect costs of rheumatoid arthritis in Brazil. Value Health. 2008;11(5):869-877.

13. Chermont GC, Kowalski SC, Ciconelli RM, Ferraz MB. Resource utilization and the cost of rheumatoid arthritis in Brazil. Clin Exp Rheumatol. 2008;26(1):24-31.

14. Arnett FC, Edworthy SM, Bloch DA, et al. The American Rheumatism Association 1987 revised criteria for the classification of rheumatoid arthritis. Arthritis Rheum. 1988;31(3):315-324.

15. Citera G, Arriola MS, Maldonado-Cocco JA, et al. Validation and crosscultural adaptation of an Argentine Spanish version of the Health Assessment Questionnaire disability index. J Clin Rheumatol. 2004; 10(3):110-115.

16. Rice DP. Cost-of-illness studies: fact or fiction? Lancet. 1994;344(8936): 1519-1520.

17. Pugner KM, Scott DI, Holmes JW, Hieke K. The costs of rheumatoid arthritis: an international long-term view. Semin Arthritis Rheum. 2000; 29(5):305-320.

18. Michaud K, Messer J, Choi HK, Wolfe F. Direct medical costs and their predictors in patients with rheumatoid arthritis: a three-year study of 7,527 patients. Arthritis Rheum. 2003;48(10):2750-2762.

19. Pineda-Tamayo R, Arcila G, Restrepo P, Tabon G, Camargo JF, Anaya JM. Impact of cardiovascular illness on hospitalization in patients with rheumatoid arthritis. Revista Colombiana De Reumatología. 2004; 11(2):89-96. Spanish.

20. Mora C, Gonzales A, Diaz J, Quintana G. Financial costs of early rheumatoid arthritis in the first year of medical attention: three clinical scenarios in a third-tier university hospital in Colombia. Biomédica. 2009;29(1):43-50. Spanish.

21. Mould Quevedo J, Pelaez Ballestas I, Vazquez Mellado J, et al. Societal costs of the most common inflammatory rheumatic diseases in Mexico from the patient's perspective. Gac Med Mex. 2008;144(3):225-231. Spanish.

22. Clarke AE, Zowall H, Levinton $\mathrm{C}$, et al. Direct and indirect medical costs incurred by Canadian patients with rheumatoid arthritis: a 12 year study. J Rheumatol. 1997;24(6):1051-1060.
23. Jonsson B, Rehnberg C, Borgquist L, Larsson SE. Locomotion status and costs in destructive rheumatoid arthritis. A comprehensive study of 82 patients from a population of 13,000. Acta Orthop Scand. 1992; 63(2):207-212.

24. Meenan RF, Yelin EH, Henke CJ, Curtis DL, Epstein WV. The costs of rheumatoid arthritis. A patient-oriented study of chronic disease costs. Arthritis Rheum. 1978;21(7):827-833.

25. Stone CE. The lifetime economic costs of rheumatoid arthritis. J Rheumatol. 1984;11(6):819-827.

26. Brennan A, Bansback N, Reynolds A, Conway P. Modelling the costeffectiveness of etanercept in adults with rheumatoid arthritis in the UK. Rheumatology (Oxford). 2004;43(1):62-72.

27. Yelin E. Work disability in rheumatic diseases. Curr Opin Rheumatol. 2007;19(2):91-96.

28. Burton W, Morrison A, Maclean R, Ruderman E. Systematic review of studies of productivity loss due to rheumatoid arthritis. Occup Med (Lond). 2006;56(1):18-27.

29. Geuskens GA, Burdorf A, Hazes JM. Consequences of rheumatoid arthritis for performance of social roles - a literature review. J Rheumatol. 2007;34(6):1248-1260.

30. Wolfe F, Allaire S, Michaud K. The prevalence and incidence of work disability in rheumatoid arthritis, and the effect of anti-tumor necrosis factor on work disability. J Rheumatol. 2007;34(11):2211-2217.

31. del Rincon ID, Williams K, Stern MP, Freeman GL, Escalante A. High incidence of cardiovascular events in a rheumatoid arthritis cohort not explained by traditional cardiac risk factors. Arthritis Rheum. 2001; 44(12):2737-2745.

32. Gonzalez A, Maradit Kremers H, Crowson CS, et al. Do cardiovascular risk factors confer the same risk for cardiovascular outcomes in patients with rheumatoid arthritis as in non-RA patients? Ann Rheum Dis. 2008; 67(1):64-69.

33. Goodson N. Coronary artery disease and rheumatoid arthritis. Curr Opin Rheumatol. 2002;14(2):115-120.

34. Lajas C, Abasolo L, Bellajdel B, et al. Costs and predictors of costs in rheumatoid arthritis: a prevalence-based study. Arthritis Rheum. 2003; 49(1):64-70
ClinicoEconomics and Outcomes Research

\section{Publish your work in this journal}

ClinicoEconomics \& Outcomes Research is an international, peerreviewed open-access journal focusing on Health Technology Assessment, Pharmacoeconomics and Outcomes Research in the areas of diagnosis, medical devices, and clinical, surgical and pharmacological intervention. The economic impact of health policy and health systems

\section{Dovepress}

organization also constitute important areas of coverage. The manuscript management system is completely online and includes a very quick and fair peer-review system, which is all easy to use. Visit http://www.dovepress.com/testimonials.php to read real quotes from published authors. 